\title{
The Possibilities of Improving Maintenance Through CMMS Data Analysis
}

\author{
Antti SALONEN ${ }^{\mathrm{a}, 1}$, Marcus BENGTSSON ${ }^{\mathrm{a}}$ and Victoria FRIDHOLM ${ }^{\mathrm{b}}$ \\ a Mälardalen University, Sweden \\ b ABB Control Products, Sweden
}

\begin{abstract}
Maintenance of production equipment is one of the most critical support actions in manufacturing companies for staying competitive. More recently, with the introduction of Industry 4.0, academia, as well as industry, put a lot of effort into condition monitoring in order to implement predictive maintenance. Most stakeholders agree that maintenance need to be more data-driven. However, in order to draw true advantage of data-driven decisions, it is necessary for manufacturing companies to have implemented basic maintenance to a high standard in order to reduce for example: recurring failures, human errors, unsafe machines, etc. The realtime data can then be used to improve efficiency of maintenance tasks and schedule that adds value to the processes.

In manufacturing industry, maintenance actions are commonly administered in a Computerized Maintenance Management System, CMMS, still, rather few companies analyze their maintenance records. Behind these data there is often a treasure of improvement opportunities that could be used to improve basic maintenance.

The purpose of this paper is to explore how historical data from a CMMS can be used in order to improve maintenance effectiveness and efficiency of activities.

In order to exemplify the possibilities of analyzing CMMS records, a case study has been performed in a plant, manufacturing driveline components for heavy construction vehicles.

The study shows that one major obstacle for utilizing the CMMS data is poor description of faults and failures when it comes to work order requests, mostly performed by operators and assemblers, as well as work order reporting, mostly performed by repairmen and maintenance technicians. However, by thorough analysis of well described corrective maintenance, it is possible for industry to understand the nature of the occurring breakdowns and thus, refine the preventive maintenance program in order to further increase the dependability of the production system.
\end{abstract}

Keywords. Maintenance improvement, Computerized maintenance managament system, CMMS, Data analytics

\section{Introduction}

Maintenance of production equipment is one of the most critical support actions in manufacturing companies for staying competitive [1,2]. This has even become more evident with the introduction of Lean production, which also has raised an awareness of the importance of maintenance effectiveness [1]. Still, Wireman [3], states that one third of the maintenance cost is wasted, due to poor planning, poor preventive maintenance (PM) and consequently use of overtime work. Other forms of maintenance related waste are: excessive/unscheduled maintenance, unplanned or unscheduled work, excessive

\footnotetext{
${ }^{1}$ Corresponding Author. antti.salonen@mdh.se
} 
and/or unnecessary activities, poor spare parts management, obsolete technology, poor quality work, poor quality spare parts, and equipment unavailability [4].

Good maintenance has been defined as when:"...seeing very few corrective maintenance events; while performing as little preventive maintenance as possible." [5, p.136]. This definition aligns with the study by Salonen and Tabikh [6], stating that the cost of an unplanned stop is about five times the cost of a planned stop. But as Salonen and Deleryd [7] and Bengtsson and Salonen [8] points out, it is also essential to avoid more planned PM than necessary. It is therefore important to find out any excessive PM in order to improve the efficiency of the maintenance program [8]. This clearly gives an incentive for analyzing unplanned stops and trying to replace them with planned maintenance actions.

In order to improve the maintenance management, it is essential to analyze the current state, as well as the historic behavior of the equipment. For this, the CMMS is essential. [9, 10]. However, on a general level, Dalle Mule and Davenport states that: "Cross-industry studies show that on average, less than half of an organization's structured data is actively used in making decisions-and less than $1 \%$ of its unstructured data is analyzed or used at all. More than 70\% of employees have access to data they should not, and $80 \%$ of analysts' time is spent simply discovering and preparing data” [11, p. 112].

Regarding maintenance data management, Labib [10] point out that operations management organizations often are weak in exploiting their equipment maintenance records. "The exploitation of the equipment maintenance records is often a weak point within an operations management organization." [12, p. 254].

The purpose of this study is to explore how historical data from a CMMS can be used in order to improve maintenance effectiveness and efficiency of activities. As support, two research questions have been formulated:

RQ1: Is the practiced data logging of adequate quality for analysis?

RQ2: Can the analysis aid in the selection of PM approaches?

\section{Theoretical background}

Preventive maintenance is defined as: "Maintenance carried out at predetermined intervals or according to prescribed criteria and intended to reduce the probability of failure or the degradation of the functioning of an item." [13, p. 12]. Failure is defined as: "Termination of the ability of an item to perform a required function." [13, p. 9] while a fault is defined as: "State of an item characterised by inability to perform a required function, excluding the inability during preventive maintenance or other planned actions, or due to lack of external resources." [13, p. 12]. Failure is thus an event wheras a fault is a state.

In order to prevent equipment breakdowns, it is imperative to understand the nature of failures. In a production system, where staff interacts with the technical system, there are two major kinds of failure causes; natural deterioration, and externally induced failures.

\subsection{Failures, due to natural deterioration}

All components have a limited lifetime. For some, the variation in lifetime is very limited, while other types of components may have a very varying lifetime, often because of 
inconsistent inherent quality. Many components, especially moving ones, show apparent degradation patterns that may be monitored through various techniques. However, e.g. electronics, does not have any detectable degradation patterns, i.e. they break without warning.

By combining these two characteristics, four categories of components may be identified, each with their specific maintenance approaches, as shown in Figure 1:

A: Breakdowns caused by failures that have regular failure frequencies without degradation failure pattern.

B: Breakdowns caused by failures that have irregular failure frequencies without degradation failure pattern.

$\mathrm{C}$ : Breakdowns caused by failures that have regular failure frequencies with degradation failure pattern.

D: Breakdowns caused by failures that have irregular failure frequencies with degradation failure pattern.

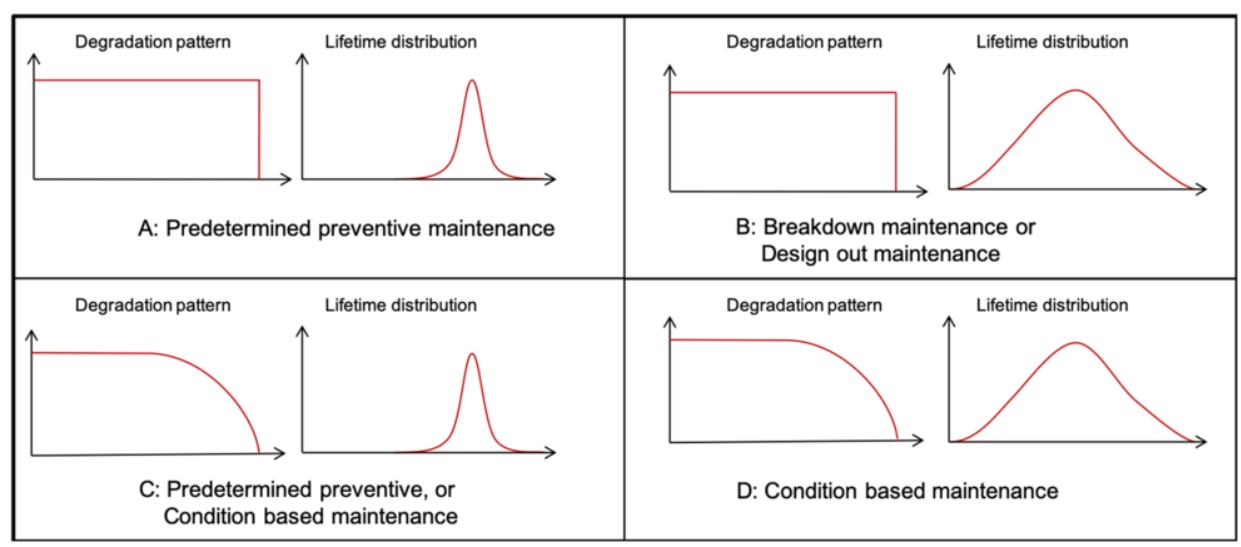

Figure 1: Combination of lifetime distributions and degradation patterns, related to feasible maintenance approaches

For components of category A, with no detectable deterioration, but a rather narrow lifetime distribution, predetermined maintenance types such as calendar based, timebased, or run-time are most suitable. Condition based maintenance, CBM, is only applicable for components with a detectable deterioration pattern. According to Moubray [14], only $20 \%$ of components show detectable degradation patterns. For components of category $\mathrm{D}$ with detectable deterioration patterns and wide spread lifetime distribution, $\mathrm{CBM}$ is the only viable approach for preventing failures, while a component with narrow lifetime distribution may be handled through predetermined preventive maintenance. Components of category B, that lack detectable deterioration and show a wide spread lifetime distribution are not possible to prevent from failing and should therefore be run to failure. For such components there may be of interest to either change the design or introduce redundancies depending on the severity of failure in terms of for instance financial-, environmental-, or safety aspects.

In reliability engineering, the lifetime distribution of components is analyzed, based on Weibull distribution. For components with a Weibull distribution with $\beta \leq 1$, 
predetermine preventive maintenance is not applicable [15]. Instead, any preventive maintenance needs to be based on other criteria, i.e. the actual condition of the component. However, this requires the presence of a set of measurements and data acquisition systems to monitor the machine performance in real time [16].

\subsection{Externally induced failures}

Except for normal aging and tear, components get damaged through external influence. Such influence may be, e.g. human errors, environmental disorders, such as lightning, or extreme heat, or faulty raw material. According to Salonen [17], 20-45\% of equipment failures in two large automotive manufacturing companies in Sweden are due to human errors. These human errors came in three categories; poor handling, poor cleaning, and poorly performed preventive maintenance [17]. The true root causes of these human errors may be due to poor planning, poor training, lack of time, lack of manpower, or poor leadership. Sheikhalishahi, et.al. [18], conclude that the most important human factors, related to maintenance are fatigue, knowledge/experience, and coordination and communication. Based on a study of how the Human Resource practices within an organization can affect human errors, Macduffie [19] points out that operators in flexible manufacturing contexts have to be multi skilled. Not only to operate, but also to perform maintenance, perform quality controls, and statistical process control. One common cause for human errors in batch producing manufacturing industry is setup changes in equipment.

Externally induced failures are often random in nature and in most cases, they do not provide any heads-up warnings. It is therefore important that these failures are treated separately when analyzing failure records in order to improve the PM.

\subsection{Computerized maintenance management systems}

Proactive maintenance management of world-class standard is close to impossible without the support of a good computer system [20]. In order to improve the program for preventive maintenance it is vital to analyze the failures that occur in the equipment [21, 22]. As a means, Labib [21] state that ideally, a CMMS may offer a platform for decision analysis, thus providing management support. Thereby, the CMMS offers the means to achieving world-class maintenance. By documenting in CMMS, data on, e.g., failure reports, disturbances, planned preventive maintenance, etc. have been used to improve maintenance efficiency and effectiveness [23]. Further Kans, et.al. [24] states: "Through logging in computerized maintenance management systems much data on, e.g., failure reports, disturbances, scheduled preventive maintenance, etc., has laid the foundation to possible maintenance efficiency and effectiveness actions." (p. 5).

In order to reduce failures, and failure recurrence, the key information to log is the failure cause [25]. However, CMMS seems to be scarcely used for analysis of maintenance records [22].

\subsection{Professional versus autonomous maintenance}

Kans, et.al. [24] also note the importance of fundamental maintenance work. Nakajima [26] argues that breakdowns are a result of the incorrect assumptions and firm perceptions of engineers, maintenance staff, and operators. The solution to this problem is to work cross-functional and divide the responsibility for the equipment. 
The idea behind the autonomous maintenance (AM) concept is that operators should feel responsibility and ownership of the production equipment they operate. The reason for AM is that operators should inspect and react to abnormalities. To achieve this, the operators need time, training, motivation and dedication. If digitalization is used correctly, technology can free up more time for operators, and inspections in AM can be automated. Knowledge can also increase with the new technology. It is emphasized that operators still need to be committed and take responsibility for the equipment. Otherwise, the technology will not reach expected output. Despite how advanced the technology is someone still needs to clean and lubricate the machinery [26].

Both professional and autonomous maintenance are thus needed to keep machine equipment running so that they can perform a required function. Professional and autonomous maintenance should exist in symbiosis and draw from each others strenght.

\section{Methodology}

The results in this paper are based on a single case study at one company, manufacturing components for heavy commercial vehicles. The production site have about 700 employees and 300 manufacturing machines, various assembly equipment, test benches, a hardening shop, and a paint shop. The maintenance department have about 70 employees and is populated by repairmen, maintenance engineers, and storage personnel. The maintenance department performes the majority of all maintenance actions by inhouse means, some actions are purchased due to competence issues. The maintenance actions performed includes: corrective maintenance (CM) in the form of both repairing breakdowns and disturbances, preventive maintenance in the form of both predetermined maintenance and condition based maintenance, improvements, and renovations. The condition monitoring techniques used consists of: vibration measurment, infrared camera, temperature measurement, ultrasonic compressed air leak detection, geometrical measurements, and electrical effects monitoring.

For the study, raw CMMS data was selected from two production cells with a total of 11 different machines. Cell $\mathrm{X}$ consists of five machining centres with integrated coolant systems, while cell $Y$ consists of six machining centres and one common coolant system. To achieve a fair comparison between the two cells, cell $\mathrm{Y}$ is treated as six machines even though the breakdown history from the coolant system is included. The machining centers and other equipment in both production cells were installed between 2007-2008. The machining centers from cell $X$ are European and the machining centers from cell Y are Asian. The production cells manufactures similar articles with cast-iron material with rather long cycle times, up to one hour. The manufacturing that the machining centers performs make-up of circular milling, drilling, and threading.

The raw data in the study consists of 386 work orders extracted from the CMMS at the case company. The case company logs all maintenance activities, such as: predetermined maintenance, CBM, disturbances, improvement work etc., however the work orders of intrest of this study are related to breakdowns. The data was downloaded for the years 2015-2017. There are different "views" in the CMMS to collect the data from, and there may be small differences in content between these views, such as the number of breakdowns included. The different views were required to acquire all needed data. To ensure that the same breakdowns were included in all views the data was cleaned before it was processed by tabulation. The cleaning process included the deleting of five multiple work-orders. 
For the analysis, historical information from the work orders has been used. However, since a large part of the information is documented in free text fields, the quality of the information varies, and therefore some work orders could not contribute to all parts of the analysis. In order to categorize each failure, seven questions were answered by a company maintenance engineer:

1. Is the failure or fault described/reported in the work order?

2. Is it a human factor that triggered the breakdown/fault?

3. Does the failure have a degradation failure pattern or not?

4. Does the failure occur in regular or irregular failure frequencies?

5. Does the failure belong to category A, B, C or D (as defined in the theory chapter)?

6. Is it possible to monitor the failure with objective or subjective monitoring technique?

7. Is the failure recurring?

\section{Findings}

The study evaluates how an analysis of CMMS data could be performed, and what conclusions could be drawn from such an analysis.

\subsection{Failure data analysis}

The work orders were distributed as shown in Table 1. Note that the X-machines breaks down almost twice as much as the Y-machines.

Table 1. The number of breakdowns per cell and per machine, 2015-2017

\begin{tabular}{ccccccc|c|c}
\hline $\mathrm{Y} 1$ & $\mathrm{Y} 2$ & $\mathrm{Y} 3$ & $\mathrm{Y} 4$ & $\mathrm{Y} 5$ & $\mathrm{Y} 6$ & $\mathrm{Y} 7$ & Total & Average \\
24 & 32 & 20 & 14 & 23 & 6 & 29 & 148 & 24.7 \\
\hline $\mathrm{X} 1$ & $\mathrm{X} 2$ & $\mathrm{X} 3$ & $\mathrm{X} 4$ & $\mathrm{X} 5$ & & & & \\
46 & 40 & 48 & 63 & 41 & & & 238 & 47.6 \\
\hline
\end{tabular}

On the other hand, it seems that the X-machines have a shorter Mean Down Time (MDT) than the Y-machines, which to some extent evens out the impact on the production, see Table 2. Both the Mean Time To Repair (MTTR) and Mean Time Waiting (MTW) which makes-up the MDT are shorter for the X-machines than for the Y-machines.

Table 2. MTW, MTTR, and MDT per cell

\begin{tabular}{ccccccccc|ll}
\hline & $\mathrm{Y} 1$ & $\mathrm{Y} 2$ & $\mathrm{Y} 3$ & $\mathrm{Y} 4$ & $\mathrm{Y} 5$ & $\mathrm{Y} 6$ & $\mathrm{Y} 7$ & Total & KPI & Hours \\
\hline $\mathrm{T}_{\mathrm{w}}$ & $115: 33$ & $234: 22$ & $113: 36$ & $63: 58$ & $96: 41$ & $82: 43$ & $28: 04$ & $734: 57$ & MTW & 4.58 \\
$\mathrm{~T}_{\mathrm{r}}$ & $345: 13$ & $585: 18$ & $140: 46$ & $341: 27$ & $211: 43$ & $184: 03$ & $82: 33$ & $1891: 04$ & MTTR & 12.47 \\
$\mathrm{Dt}$ & $460: 46$ & $819: 40$ & $254: 22$ & $405: 25$ & $308: 24$ & $266: 46$ & $110: 37$ & $2626: 01$ & MDT & $17: 45$ \\
\hline \multicolumn{1}{|l}{} & $\mathrm{X} 1$ & $\mathrm{X} 2$ & $\mathrm{X} 3$ & $\mathrm{X} 4$ & $\mathrm{X} 5$ & & & Total & KPI & Hours \\
\hline $\mathrm{T}_{\mathrm{w}}$ & $216: 50$ & $161: 30$ & $184: 48$ & $309: 42$ & $103: 43$ & & & $976: 34$ & MTW & 4.06 \\
$\mathrm{~T}_{\mathrm{r}}$ & $475: 19$ & $376: 50$ & $563: 49$ & $108: 36$ & $378: 24$ & & & $1902: 58$ & MTTR & 8.0 \\
$\mathrm{Dt}$ & $692: 09$ & $538: 20$ & $748: 37$ & $418: 18$ & $482: 07$ & & & $2879: 31$ & MDT & 12.06 \\
\hline
\end{tabular}




\subsubsection{Work order data quality}

When analyzing the data through the categorization questions, it became clear that a lot of the work orders lacks information on the failure description and to some extent even on what has been the fault. As work orders with weak or non-existing failure descriptions are impossible to analyze only those work orders which contain enough information making it possible to analyze has been taken into consideration. Table 3 presents the number of work order that contain a clear failure description. As will be shown below, even though some work orders has lacked failure description some categorization questions have been possible to answer.

Table 3. To what extend is the failure described in the work orders to the studied breakdown

\begin{tabular}{cccc}
\hline Machine type & $\begin{array}{c}\text { Total number of work } \\
\text { orders (WO) }\end{array}$ & $\begin{array}{c}\text { WO containing failure } \\
\text { description }\end{array}$ & \% Failure descriptions \\
\hline Y & 148 & 71 & $48 \%$ \\
X & 238 & 131 & $55 \%$ \\
\hline Total & 386 & 202 & $52 \%$
\end{tabular}

\subsubsection{Human errors}

It is important to consider human errors as a root cause category. Failures caused by human errors are not preventable through traditional maintenance approaches, but rather through training and/or education of the staff. Table 4 presents the number of work order caused by human errors.

Table 4. Failures due to human errors

\begin{tabular}{cccc}
\hline Machine type & Can be evaluated & Caused by human errors & $\%$ human factors \\
\hline Y & 71 & 15 & $21 \%$ \\
X & 131 & 25 & $19 \%$ \\
\hline Total & 202 & 40 & $20 \%$
\end{tabular}

It is also interesting to note that $80 \%$ of the failures caused by human errors occurred more than once, indicating that they may be caused by lack of knowledge, rather than occasional mistakes. Table 5 presents the number of recurring fault caused by human errors.

Table 5. Re-occurring faults, caused by human errors

\begin{tabular}{cccc}
\hline Machine type & Number of human errors & $\begin{array}{c}\text { Number of recurring } \\
\text { faults }\end{array}$ & $\begin{array}{c}\text { \% recurring faults caused } \\
\text { by human errors }\end{array}$ \\
\hline Y & 15 & 11 & $73 \%$ \\
X & 25 & 21 & $84 \%$ \\
\hline Total & 40 & 32 & $80 \%$
\end{tabular}

\subsubsection{Degradation patterns}

In order to utilize CBM on a component, it must have a detectable degradation pattern. Of the 210 analyzable work orders, $59 \%$ were regarding as having a failure with a detectable deterioration pattern, see Table 6 . 
Table 6. Faults with degradation patterns

\begin{tabular}{cccc}
\hline Machine type & Can be evaluated & $\begin{array}{c}\text { Degradation pattern } \\
\text { present }\end{array}$ & $\begin{array}{c}\text { \% degradation pattern } \\
\text { present }\end{array}$ \\
\hline Y & 74 & 44 & $59 \%$ \\
$\mathrm{X}$ & 136 & 80 & $59 \%$ \\
\hline Total & 210 & 124 & $59 \%$
\end{tabular}

\subsubsection{Lifetime distribution}

204 work orders could be evaluated from a lifetime distribution perspective, of these $19 \%$ involved failures with a periodic failure frequency, implying that the lifetime distribution is rather narrow, see Table 7.

Table 7. Faults with periodic failure frequencies

\begin{tabular}{cccc}
\hline Machine type & Can be evaluated & $\begin{array}{c}\text { Periodic failure } \\
\text { frequency }\end{array}$ & $\begin{array}{c}\text { \% periodic failure } \\
\text { frequency }\end{array}$ \\
\hline Y & 71 & 15 & $21 \%$ \\
X & 133 & 23 & $17 \%$ \\
\hline Total & 204 & 38 & $19 \%$ \\
\hline
\end{tabular}

\subsubsection{Combined failure characteristics}

208 work orders were possible to categorize according to the four failure categories presented in section 1.1.

Table 8. Categorization of faults

\begin{tabular}{cccccccccc}
\hline Machine type & $\begin{array}{c}\text { Can be } \\
\text { evaluated }\end{array}$ & A & B & C & D & \% A & $\%$ B & \% C & $\%$ D \\
\hline Y & 72 & 4 & 29 & 13 & 26 & $6 \%$ & $40 \%$ & $18 \%$ & $36 \%$ \\
X & 136 & 2 & 56 & 21 & 57 & $2 \%$ & $41 \%$ & $15 \%$ & $42 \%$ \\
\hline Total & 208 & 6 & 85 & 34 & 83 & $3 \%$ & $41 \%$ & $16 \%$ & $40 \%$
\end{tabular}

\subsubsection{Condition monitoring technique applicability}

In addition to study if a failure have a detectable degradation, it is also interesting to study whether the condition monitoring could be performed through objective or subjective monitoring techniques. Only objective monitoring techniques that at the time of the analysis were in use at the case company were taken into consideration, therefore some failures which are analyzed as having a degradation pattern are neither analyzed as being possible to monitor by either objective nor subjective monitoring techniques. See Table 9 and 10 for a summation on the results.

Table 9. Faults possible to monitor with objective CM-techniques

\begin{tabular}{cccc}
\hline Machine type & Can be evaluated & Objective CM applicable & \% Objective CM \\
\hline Y & 71 & 15 & $21 \%$ \\
X & 133 & 36 & $27 \%$ \\
\hline Total & 204 & 51 & $25 \%$
\end{tabular}


Table 10. Faults possible to monitor with subjective CM-techniques

\begin{tabular}{cccc}
\hline Machine type & Can be evaluated & Subjective CM applicable & \% Subjective CM \\
\hline Y & 75 & 43 & $57 \%$ \\
X & 136 & 61 & $45 \%$ \\
\hline Total & 211 & 104 & $49 \%$
\end{tabular}

\subsubsection{Recurring failures}

The last question in the categorization process is to determine if a failure is recurring, see Table 11. If failures are recurring there is a need to investigate how they can be eliminated. This elimination might be done by applying some sort of PM action but solutions may very well also be found in education and competence development to eliminate human errors, redesign of assets etc.

Table 11. Number of recurring failures

\begin{tabular}{cccc}
\hline Machine type & Can be evaluated & Recurring failures & \% Recurring failures \\
\hline Y & 129 & 104 & $81 \%$ \\
X & 214 & 164 & $77 \%$ \\
\hline Total & 343 & 268 & $78 \%$
\end{tabular}

\section{ANALYSIS}

An analysis of the findings clearly show how the industry can improve their maintenance activities by analyzing the CMMS data. It is though neceassary to improve the logging procedures in order to strengthen the data quality.

\subsection{Quality of data from CMMS}

Several authors point out the potential in utilizing CMMS data for improvement of maintenance management $[20,21,22,23,24]$. However, this implies that the data is of sufficient quality. The studied data set contained 386 separate work orders, extracted out of the CMMS of the case company. Of these work orders, only 202 contained a sufficient failure description. This fact limits the possibilities of root cause analysis of the failures, thus making elimination of the causes impossible or very difficult at best.

\subsection{Failure due to human errors}

Of the 202 work-orders that included a sufficient failure description, 20\% were caused by human errors. Of these errors, the majority was caused by lack of or poorly performed AM, e.g., poor cleaning or poor lubrication. As Salonen [17] points out, a decreasing number of operators, and an increased number of tasks and responsibilities delegated to shop floor, puts a hard strain on the operators. Notable is the fact that in one of the machines, $34 \%$ of the breakdowns were caused by the operators making incorrect restarts after power-outs. This clearly indicates that the operators need better instructions and processes for handling deviations. An important finding is that $80 \%$ of the brekdowns, caused by human errors were recurring. This clearly indicate that the operators are repeating the errors. 


\subsection{Failure characteristics in context of maintenance types}

Through the analysis of lifetime distribution and degradation patterns some interesting results emerge. The A-category components, suitable for predetermined preventive maintenance were only made-up of 3\%. It is important to realize is that this is an analysis of failing components, so a conclusion is that most components, suitable for predetermined preventive maintenance are getting that already. What is important to mention is that some of these components probably are over maintained, causing waste of time and money [8]

The B-category stood for $41 \%$ of the breakdowns. This kind of errors are not possible to prevent through technical maintenance activities. Instead, a study needs to be performed in order to see if they are financially just to eliminate through modifications or re-design of the equipment. Othervise, the only viable strategy is to minimize the consequences of these failures. Of course, there are failures in this category, caused by human errors. These should be possible to reduce through, e.g. improved instructions and/or better training.

The C-category failures make-up $16 \%$ of the analyzed data. Also for these failures a feasability study should be performed in order to determine wether to use CBM or predetermined preventive maintenance.

In the analysis, $40 \%$ of the failures were of category $\mathrm{D}$ and thus preventable only by CBM. Still, for these failures, a feasability study needs to be performed in order to assess wether it is financially just to implement condition monitoring on each of the failures.

Moubray [14, p.155] states that "... it is not unusual to find that condition monitoring as defined in this part of this chapter is technically feasible for no more than $20 \%$ of failure modes, and worth doing in less than half these cases." This study shows a higher number than [14]. The main reason for this, is probably that the study is based on actual breakdowns, while Moubrey's statement is based on all possible breadowns, including those that are effectively prevented. If the case company, effectively prevents components lacking deterioration patterns, from breaking, the percentage of components, feasible for $\mathrm{CM}$ increases within the remaining population.

The organizational need of Root Cause Failure Analysis (RCFA) is based on the information in table 11 , showing that $78 \%$ of the errors were recurring. This indicates that $78 \%$ could be prevented from recurring through root cause failure analysis. While $56 \%$ could have been prevented or predicted with CBM, this shows how vital RCFA and improvement processes still are to reach both effectiveness and efficiency [8]. As such, it is necessary to work on both basic maintenance actions, such as for instance RCFA and predetermined maintenance, as well as more of high technological advancement [27].

An important insight from the study is that a statistical analysis require a fair amount of machines. The study is based on 3 years of data from 11 machining systems and a total of 386 work orders related to breakdowns. This gives an average of 11.7 breakdowns per machine and year. For a smaller company it will probably be much harder to get a valid and reliable amount of data for statistical analysis. 


\section{Discussion}

Investigating only one case company and only 11 machines makes generalization impossible. It has not been the purpose of the study either. The study can still give some insights into how industrial companies may analyze and utilize the data in a CMMS in finding improvement potential in maintenance. The study can also give some insight in how the reporting in the CMMS may be improved so that the data may be better utilized in future endeavors.

In revisiting the research questions it can be concluded that at this particular case company and at these particular machines there is a problem of quality in the logging of CMMS. The fact that almost $50 \%$ of all work orders related to breakdowns lacks a clear description of failure or fault makes it difficult to run analysis with a good validity. This result vislualizes that the company lacks a standardized process for reporting and reporting back work orders. Also, it can be suspected that education and training in how to do reporting and reporting back into the CMMS is lacking. General improvement potentials for the case company is to improve the input data in the CMMS.

Even though there can be lots to discuss and wish for of the quality of the data in the CMMS several conclusions regarding these pilot machines can be drawn. As failures and work orders of these failures has been the object of the study and not components or subsystems it may be difficult to generate clear improvement suggestions on PM actions based on the results. However, it has been clearly established that the case company suffers from recurring breakdowns as well as human errors, and could possibly increase its use of condition monitoring to increase maintenance effectiveness and efficiency. Recurring failures can be mitigated by, for instance, competence development, rootcause failure analysis and elimination, improvement work etc., that is, rather basic activitives. Human errors can be mitigated by, for instance, competence development, poka-yoke devices, etc., also rather basic activities. It is adviced that the case company first attempts to improve the basic foundation of maintenance, such as competence development and root-cause failure analysis, before embarking on implementation of additional condition monitoring activities as these basic foundation might reduce the need for implementation of technical tools.

\section{Acknowledgement}

This paper is based on a Master Thesis study, conducted within the project Data Analytics In Maintenance Planning, DAIMP, which was funded by Vinnova FFI, the research work is also a part of the initiative for Excellence in Production Research (XPRES).

\section{References}

[1] A. Salonen, and M. Bengtsson, The Potential in Strategic Maintenance Development Journal of Quality in Maintenance Engineering, Vol. 17, No. 4, 2011, pp. 337-350

[2] K. Fraser, H. Hvolby, and T. Tseng, Maintenance management models: a study of the published literature to identify empirical evidence. International Journal of Quality \& Reliability Management, 32(6), 2015, pp. 635-664.

[3] T. Wireman, World Class Maintenance Management, Industrial Press, New York, NY, 1990. 
[4] R.P. Mohanty, and S.G. Deshmukh, Managing green productivity: a case study, Work Study, Vol. 48, No. 5, 1999, pp.165-169.

[5] R. Cooke, and J. Paulsen, Concepts for Measuring Maintenance Performance and Methods For Analysing Competing Failure Modes. Reliability Engineering and System Safety, 5(2), 1997, pp. 135141.

[6] A. Salonen, and M. Tabikh, Downtime costing - Attitudes in Swedish Manufacturing Industry, In Proceedings of the 10th World Congress on Engineering Asset Management, Tampere, 2015, p. 539544.

[7] A. Salonen, and M. Deleryd, Cost of Poor Maintenance - A concept for maintenance performance improvement, Journal of Quality in Maintenance Engineering, Vol. 17, No. 1, 2011, pp. 63-73.

[8] M. Bengtsson, and A. Salonen, Requirements and Needs-A Foundation for reducing maintenancerelated waste. In Proceedings of the 10th World Congress on Engineering Asset Management, Tampere,2015, pp. 105-112.

[9] S.O. Duffuaa, and A. Raouf, Planning and Control of Maintenance Systems, Springer International Publishing Switzerland, 2015

[10] A. Labib, A decision analysis model for maintenance policy selection using a CMMS, Journal of Quality in Maintenance Engineering, 10(3), 2004, 191-202

[11] L. DalleMule, and T.H. Davenport, What's your data strategy. Harvard Business Review, 95(3), 2017, pp. 112-121.

[12] A. Crespo Márquez, and A. Sánchez Herguedas, Learning about failure root causes through maintenance records analysis, Journal of Quality in Maintenance Engineering, 10, 2004, pp. 254-262

[13] Maintenance terminology, SS-EN 13306, 2010

[14] J. Moubray, Reliability-centered maintenance. Industrial PressInc, New York, 1997

[15] A.K. Jardine, and A.H. Tsang, Maintenance, replacement, and reliability: theory and applications. CRC press, Boca Raton, 2005.

[16] M. Bevilacqua, and M. Braglia, The analytic hierarchy process applied to maintenance strategy selection. Reliability Engineering \& System Safety, 70(1), 2000, pp. 71-83.

[17] A. Salonen, The need for a holistic view on dependable production systems. In Proceedings of the $8^{t h}$ Swedish Production Symposium, Stockholm, Sweden. Published in Procedia Manufacturing Volume 25 2018, pp. 17-22.

[18] M. Sheikhalishahi, L. Pintelon, and A. Azadeh, Human factors in maintenance: a review, Journal of Quality in Maintenance Engineering, vol. 22, Issue 3, 2016, pp. 218-237.

[19] J. Macduffie, Human Resource Bundles and Manufacturing Performance: Organizational Logic and Flexible Production Systems in the World Auto Industry. Industrial and Labor Relations Review, 48(2), 1995 , pp. 197-221

[20] M. Wienker, K. Henderson, and J. Volkerts, The Computerized Maintenance Management System an Essential Tool for World Class Maintenance. Procedia Engineering, 138, 2016, pp. 413-420.

[21] A. Labib, World class maintenance using a computerized maintenance management system, Journal of Quality in Maintenance Engineering, Vol. 4, No. 1, 1998, pp. 66-75

[22] A. Garg, and S.G. Deshmukh, Maintenance management: literature review and directions. Journal of Quality in Maintenance Engineering, 12(3), 2006, pp.205-238.

[23] M. Kans, The advancement of maintenance information technology: A literature review", Journal of Quality in Maintenance Engineering, Vol. 15 Issue: 1, 2009, pp.5-16

[24] M. Kans, J. Campos, A. Salonen, and M. Bengtsson, The Thinking Industry-An approach for Gaining Highest Advantage of Digitalisation within Maintenance. Journal of Maintenance Engineering, 2, 2017, pp. $147-158$.

[25] M. Rausand, and K. Øien, The basic concepts of failure analysis, Reliability Engineering and System Safety, 53, 1996, pp. 73-83

[26] S. Nakajima, TPM Development Program: Implementing Total Productive Maintenance. Preventative Maintenance Series. Productivity press, Cambridge, Mass, 1989

[27] M. Bengtsson, and G. Lundström, On the importance of combining "the new" with "the old" - One important prerequisite for maintenance in Industry 4.0, In Proceedings of the $8^{\text {th }}$ Swedish Production Symposium, Stockholm, Sweden. Published in Procedia Manufacturing Volume 25 (2018), pp. 118-125. 